\title{
Participação social de lideranças comunitárias em um contexto de desigualdade social e no enfrentamento da pandemia da COVID-19: um enfoque psicossocial'
}

\section{Social participation of community leaders in a context of social inequality and in the coping of the COVID-19 pandemic: a psychosocial approach}

\author{
Hailton Yagiu ${ }^{a}$ \\ (iD) https://orcid.org/0000-0002-3860-2061 \\ E-mail: hyagiuœgmail.com \\ Carlos Roberto Castro-Silva ${ }^{a}$ \\ (i) https://orcid.org/0000-0002-8880-1042 \\ E-mail: carobert3ळhotmail.com

\section{Antonio Euzebios Filho ${ }^{b}$} \\ (D) https://orcid.org/0000-0002-5276-3697 \\ E-mail: antonioeuzebiosळgmail.com

\section{Sueli Terezinha Ferrero Martinc} \\ (D) https://orcid.org/0000-0002-5874-063X \\ E-mail: suelitfmartinळgmail.com

\begin{abstract}
aniversidade Federal de São Paulo (UNIFESP), Instituto Saúde
\end{abstract} \\ e Sociedade - Campus Baixada Santista, Departamento de \\ Políticas Públicas e Saúde Coletiva. Santos, SP. Brasil. \\ bUniversidade de São Paulo (USP), Instituto de Psicologia, \\ Departamento de Psicologia Social e do Trabalho. São Paulo, \\ SP. Brasil. \\ 'Universidade Estadual Paulista Júlio de Mesquita Filho (UNESP). \\ Faculdade de Medicina de Botucatu, Departamento de \\ Neurologia, Psicologia e Psiquiatria. Botucatu, São Paulo, Brasil.
}

\section{Correspondência}

Hailton Yagiu

Rua Silva Jardim, 136, térreo. Santos, SP, Brasil. CEP II015-020.

\section{Resumo}

Pesquisa realizada no âmbito de um amplo projeto de pesquisa-participante em contextos de vulnerabilidade da Baixada Santista/SP, que objetiva compreender elementos psicossociais da participação social e do envolvimento das lideranças comunitárias de uma comunidade periférica local, apontando suas potencialidades e fragilidades. Atualiza as reflexões baseando-se nas ações de enfrentamento à pandemia da COVID-19 que tem acirrado as consequências da desigualdade social. Sistematiza as informações por meio do software Atlas.ti e analisa com base na perspectiva da Epistemologia Qualitativa e da Hermenêutica de Profundidade (HP) de Thompson. Resultados indicam que, de modo geral, a participação social se efetiva por meio de organizações sociais. Por um lado, a fragmentação das forças locais e esgarçamento de laços sociais dificultam o fortalecimento da participação social, por outro, os processos de conscientização estão presentes na busca do bem comum.

Palavras-chave: Desigualdade Social; Vulnerabilidade; Participação Social; Lideranças Comunitárias; COVID-19.

Este estudo é um desdobramento das pesquisas "Ética do cuidado e construção de direitos: acolhimento psicossocial em práticas da saúde da família em situações de exclusão social” (fomentada pela Fundação de Amparo à Pesquisa do Estado de São Paulo (Fapesp), n 2016/23973-2), "Desigualdade social e subjetividade: trajetórias de vida e lutas por melhores condições de vida e saúde em território vulnerável da Baixada Santista” (apoiada pelo Conselho Nacional de Desenvolvimento Científico e Tecnológico (CNPq), nº 407836/2016-o), que foram aprovadas pelo Comitê de Ética em Pesquisa da Universidade Federal de São Paulo, pareceres 2.198.202 e 2.047.444, e "Ética do cuidado e processos psicossociais de participação social em práticas da saúde da família em situações de exclusão social” (Bolsa Produtividade $\left.\mathrm{CNPq} \mathrm{n}^{\circ} 308730 / 2019-4\right)$. 


\section{Introdução}

This study was conducted within the scope of a broad research-participant project in vulnerable contexts of Baixada Santista, in the coastal region of the state of São Paulo, Brazil, which aims at understanding the psychosocial elements of social participation and the involvement of community leaders in a local peripheral village pointing their strengths and weaknesses. This article updates the reflections based on the actions to confront the COVID-19 pandemic, which has aggravated consequences of social inequality. It also systematizes information through Atlas.ti software and analyzes them based on the perspective of Qualitative Epistemology and Thompson's Depth Hermeneutics (HP). The results indicate that social participation takes place by social organizations. On one side, the fragmentation of local forces and the strengthening of social bond make it difficult to strengthen social participation; on the other side, awareness processes are present in the search for the common good.

Keywords: Social Inequality; Social Vulnerability; Social Participation; Community Leadership; COVID-19.
A ideologia dominante tem ignorado o cenário de pobreza e as desigualdades sociais produzidas pelo capitalismo, ao propagar o modo de vida individualista burguês como parâmetro da noção de sucesso ou fracasso, medidos pela régua da meritocracia. No entanto, a realidade não nos deixa enganar: o abismo entre ricos e pobres tem se tornado cada vez mais evidente no neoliberalismo - ainda mais se tratando de um país como o Brasil, um dos campeões da desigualdade de renda (WSR, 2020), em um momento em que as condições sociais se deterioram com a precarização dos direitos sociais e desrespeito aos direitos humanos.

O patriarcalismo e o patrimonialismo (Mergen; Zanetti; Reschilian, 2018), a escravização dos africanos (Gohn, 2019) e sua exploração por quase quatro séculos contribuiu para manter atual a questão das desigualdades sociais (Moura, 2019), inclusive, depois da abolição este contingente não pôde ingressar no mercado de trabalho devido à falta de políticas estatais que os incluísse enquanto cidadãos.

No Brasil os processos participativos são marcados por uma contradição, se a Constituição de 1988 possibilitou o fortalecimento da democracia pelo surgimento dos movimentos sociais, ainda há um grande desafio quanto à deslegitimação destes pelos setores hegemônicos tradicionais da sociedade.

No entanto, são as lutas sociais que efetivamente tocam nas feridas das desigualdades sociais, que atualizam e fazem avançar as políticas públicas. Desta forma, a participação social se torna um importante objeto de reflexão científica.

Propomos, neste artigo, compreender aspectos da participação social e envolvimento político de lideranças comunitárias de uma comunidade periférica da Baixada Santista, observando elementos psicossociais que dizem respeito ao papel dos processos de socialização na potencialização das ações coletivas.

Nesta perspectiva, nosso objetivo será o de apontar algumas das fragilidades e potencialidades expressas nas formas de organização e socialização comunitárias, observando os processos participativos que marcam o histórico de lutas e práticas das lideranças atuantes, e em seguida ilustrar como as potencialidades contribuíram para enfrentar a chegada da pandemia da COVID-19, uma vez que 
esta tem acirrado as desigualdades sociais em comunidades vulneráveis devido à impossibilidade de observação de alguns aspectos importantes para o controle da pandemia (Rodrigues et al., 2020), em virtude da carência de condições de higiene e da dificuldade de isolamento social pelas condições de moradia e pelo necessário deslocamento para as atividades de trabalho e de sobrevivência.

Compreendemos que a participação social é definida como uma ação que ocorre no âmbito institucional e nos movimentos sociais de forma paralela ou simultânea; desenvolve, dependendo da sua formação e caráter, do contexto social e histórico, lógicas de deliberação e representação internas e perante a sociedade e/ou Estado; uma de suas dimensões é a psicossocial, sendo este o enfoque do conceito de conscientização proposto por Martín-Baró (1997), apoiado em Paulo Freire (1979), que retomaremos adiante.

A conscientização, para este autor, é um processo que se caracteriza por diferentes graus de participação e envolvimento político, que dizem respeito às diversas formas de gerar aproximação e/ou distanciamento entre identidades pessoais e coletivas que são produzidas nas relações dos sujeitos políticos com um grupo, movimento, coletividade ou entidade (Martin-Baró, 2017; Vieira; Ximenes, 2008). São nestas relações que emergem as figuras das lideranças, sendo elas mais ou menos democráticas, fomentando graus distintos de participação social, fortalecendo uma determinada forma de relatar a história coletiva.

As periferias do capitalismo são os locais onde se tornam mais explícitas as contradições daquilo que diz a Constituição fundada sob a égide do Bem-Estar Social e sua operacionalização, especialmente em países cujas origens provém da colonização e patriarcalismo e que institucionalizaram a violência política como método de enfrentamento aos movimentos de resistência e defesa dos direitos sociais. ${ }^{2}$

Recente revisão de literatura sobre a participação social e política no Brasil (Delenogare; Araújo, 2018) observou que a maioria dos estudos procura compreender seu desenvolvimento a partir das influências histórico-culturais e políticas; das diferentes formas, dos espaços e atores; dos efeitos produzidos nas necessidades coletivas, destacando como limitações a falta de espaço nas agendas governamentais, as restritas ações institucionais e falta de engajamento dos sujeitos e apontando para a necessidade da ampliação da relação entre sociedade e gestores, criação de formas de promoção da participação social e dos sujeitos se apropriarem destas.

Segundo Aguiar (2000), um dos fatores que favoreceram o enfraquecimento dos movimentos de participação social foi o legado da colonização portuguesa, em que seus dirigentes administravam o país privilegiando os interesses próprios, burlando, dessa forma, a separação entre o público e o privado.

Estas perspectivas apontam, a nosso ver, para a necessidade de examinar e aprofundar a compreensão dos processos participativos calcados na qualidade dos vínculos e as relações intersubjetivas.

A possibilidade que encontramos nas teorizações da psicologia sócio-histórica quanto à valorização do conceito da afetividade nos aproxima das vivências concretas, faz da convivência e das histórias de vida dos sujeitos e grupos, indicadores do potencial transformador da realidade. Isto permite a compreensão da produção de subjetividade dialeticamente articulada com as vivências em seu meio social e destaca o aspecto político da participação social (Sawaia, 2014).

Segundo Sawaia (2003), a psicologia sóciohistórica compreende a construção dos vínculos sociais como um fenômeno indissociado das relações políticas estabelecidas em uma sociedade que se estrutura a partir da pobreza e da violência, onde as relações de poder e assimetria aparecem como padrão social - produzindo, inclusive, afetos, promovendo aproximações e dissidências no plano ético e político.

A escolha pela psicologia sócio-histórica envolve também uma concepção política, pois desde o seu surgimento no país ela colocou em questão e combateu a colonização da psicologia social pelas teorias norte-americanas e europeias, mostrando ser possível a compreensão das singularidades de nossa realidade a partir de marcos teóricos formulados no contexto latino-americano.

\footnotetext{
2 YAGIU, H.; CASTRO-SILVA, C. R. Social participation and empowerment in vulnerable communities: scoping review. Revista Psicologia Política. No prelo. 2020.
} 
Método

O foco das pesquisas ${ }^{3}$ realizadas em territórios vulneráveis da Baixada Santista se concentrou sobre as relações entre a unidade de saúde e a comunidade, contribuindo, desta forma, para uma concepção ampliada de saúde. Suas determinações sociais tornaram-se um referencial importante para a compreensão da complexidade de processos de saúde-doença e cuidado nestes territórios.

Esta perspectiva metodológica orienta nossas atividades desde 2009 e as questões que motivaram as pesquisas surgiram da inserção diversificada dos pesquisadores no ensino, extensão e pesquisa desenvolvidas em consonância com o Projeto Político Pedagógico da Universidade Federal de São Paulo, campus Baixada Santista (Unifesp/BS), na busca de sentidos e significados compartilhados sobre a compreensão da saúde, do cuidado e processos participativos em territórios de vulnerabilidade social (Anhas; Rosa; Castro-Silva, 2018).

Os referidos projetos na condição de "guardachuvas" possibilitaram o surgimento de outros, entre eles a dissertação de mestrado de um dos autores, a partir do qual foi possível atualizar as informações sobre as consequências da pandemia da COVID-19 neste território.

Por tratar-se de um estudo das relações sociais, representações e percepções de sujeitos e nossa fonte ser constituída por um banco de dados, definimos como o método mais adequado para a compreensão do objeto de estudo a abordagem qualitativa, pois esta possibilita sistematizar o conhecimento de como os seres humanos vivem, sentem e pensam. Adotou-se ainda o modelo documental por tratar-se de fontes primárias e pela qualidade das informações que este método possibilita que sejam extraídas dos documentos, com isso, contribuindo para a compreensão do objeto estudado.

Teórica e metodologicamente esta investigação fundamenta-se na psicologia sócio-histórica que assenta bases no marxismo, tendo o materialismo histórico e a lógica dialética como filosofia e método, compreendendo o ser humano como ser social e histórico e a sociedade enquanto produto da relação entre eles (Bock, 2011).

\section{Construção da informação qualitativa: local, participantes e coleta das informações}

A comunidade onde se realizou o estudo está localizada entre o Rio Casqueiro e a Rodovia Anchieta, é atualmente a segunda maior favela de um município da Baixada Santista e é construída sobre manguezais, o que revela a complexidade de sua urbanização em relação à preservação do meio ambiente e condições de vida. Em termos da presença do Estado no território, conta apenas com uma Unidade de Saúde de modelo misto composta por três equipes de saúde da família. Existem ainda uma creche, uma igreja e as organizações de base comunitária.

A maior parte das habitações é formada por palafitas construídas próximas umas às outras e os moradores convivem com saneamento básico precário, ausência de opções de lazer e socialização, violência da criminalidade do tráfico de drogas e um alto índice de gravidez juvenil (Anhas; Castro-Silva, 2017). As referências mais recentes do Índice Paulista de Vulnerabilidade Social a colocam no grupo de vulnerabilidade muito alta - aglomerados subnormais (IPVS, 2018).

Segundo dados do Instituto Brasileiro de Geografia e Estatística (IBGE, 2010), sua população estimada é de 128.748 habitantes, e destes, $57,9,1 \%$ são pardos e $8 \%$ negros; sua principal atividade econômica são as indústrias petroquímicas instaladas na década de 1950, que a colocam, segundo o levantamento do Observatório de Informações Municipais (Bremaeker, 2019), entre os municípios mais ricos do país com uma receita orçamentária anual superior a R\$ 1 bilhão (Carro, 2020). Entretanto, segundo Anhas (2019), 54,02\% de sua população vive e reside em condições precárias ou de risco.

Para este estudo analisou-se um banco de dados composto pelas informações coletadas no período entre junho de 2017 e outubro de 2019 através de cinco oficinas, vinte e quatro diários de campo, e das

\footnotetext{
3 Trata-se dos projetos de pesquisa "Desigualdade social e subjetividade: trajetórias de vida e lutas por melhores condições de vida e saúde em território vulnerável da baixada santista" (Conselho Nacional de Desenvolvimento Científico (CNPq) nº 407836/2016-o) e "Ética do cuidado e construção de direitos: acolhimento psicossocial em práticas da saúde da família em situações de exclusão social” (Fundação de Amparo à Pesquisa do Estado de São Paulo (Fapesp) nº 2016-23973-2).
} 
entrevistas em profundidade com quatro lideranças, sendo três mulheres e um homem. Uma delas atua em uma instituição filantrópica na comunidade, outra é aposentada e complementa sua renda através de uma mercearia no local, outra é aposentada e o outro trabalha na atividade pesqueira, além de fazer bicos. Todos possuem nível básico incompleto de escolaridade e faixa etária entre 30 e 65 anos.

As técnicas utilizadas foram: pesquisa de dados oficiais e análise documental; oficinas temáticas; formação de grupos de pesquisa para entrevistas em profundidade; observação participante e os diários de campo. A formação de grupos de pesquisa ocorreu em quatro etapas desde as reuniões para a apresentação do projeto, passando pela formação do grupo de pesquisa até o desenvolvimento da pesquisa e discussões dos resultados.

As entrevistas e as oficinas foram gravadas e transcritas deacordo como Termo de Consentimento Livre e Esclarecido aprovado pelo Comitê de Ética em Pesquisa da Universidade Federal de São Paulo - CEP/Unifesp $\mathrm{n}^{0}$ 66235417.3.0000.5505, $\mathrm{n}^{0} 68720217.8 .0000 .5505 \mathrm{e}$ $\mathrm{CEP} \mathrm{n}^{\circ}$ 2.108.711 e $\mathrm{n}^{\circ}$ 2.198.202.

Em uma etapa posterior de atualização das reflexões com base nas consequências da pandemia da COVID-19, foram realizadas entrevistas semiestruturadas à distância com as lideranças da comunidade por meio de aplicativos multiplataforma de mensagens (WhatsApp, Telegram) ou softwares de comunicação (Skype, Zoom). As entrevistas foram gravadas de acordo com o Termo de Consentimento Livre e Esclarecido aprovado pelo Comitê de Ética em Pesquisa da Universidade Federal de São Paulo - CEP/UNIFESP no 4.530 .562 e armazenadas em arquivos digitais para estudo e análise, não houve necessidade de transcrição uma vez que o software de gerenciamento possibilita a inclusão de arquivos em forma de áudio.

\section{Gerenciamento e análise das informações}

A organização e o gerenciamento das informações foram feitos pelo próprio pesquisador através do software Atlas.ti e analisados segundo a metodologia da Hermenêutica de Profundidade (Demo, 2012; Thompson, 2000).

À análise dos dados, associamos a Epistemologia Qualitativa (González-Rey, 2011) que compreende as referências orientadoras das análises como parte de um processo contínuo de aprofundamento nas informações, valorizando a implicação do pesquisador e sua criatividade e favorecendo o surgimento de novas teorizações.

\section{Resultados e discussão}

Analisamos as narrativas das lideranças comunitárias nos processos participativos que marcam o histórico de lutas pela melhoria das condições de vida, apontando algumas potencialidades e fragilidades expressas nas formas de organização e socialização comunitárias, e apresentamos algumas questões contextualizadas pelas consequências da pandemia da COVID-19.

\section{Fragilidades expressas nas formas de organização e socialização e nos processos participativos das lideranças da comunidade}

A participação social se materializa como força coletiva "que cresce em potência tanto mais se molda aos diferentes relevos e contornos, valorizando os modos e os momentos das comunidades em que se produz" (Costa; Castro-Silva, 2015, p. 288), cuja qualidade está associada à possibilidade de formação de vínculos com o objetivo de reivindicar ou criar formas afirmativas de superação da violação dos direitos (Costa; Castro-Silva, 2015: Gohn, 2019; Lavalle, 2011). Todavia, a falta de entrosamento e mobilização das pessoas representa uma das grandes dificuldades.

O discurso da Martina foi bastante emocionante. Ela falou que as pessoas precisam se preocupar, então é desafiadora a questão da participação. Para Martina, as pessoas não sentem como se a cidade fosse delas. $\varepsilon$ como se ela não fosse nossa. Ela falou que a gente precisa se sentir pertencido à cidade pra passar a lutar por essas questões ambientais e de saúde, tão importantes. (Diário de Campo, 28 de março de 2018)

Benkos comenta sobre a dificuldade em se organizar politicamente na comunidade. Ele sempre se refere aos líderes como "aqueles que se dizem líderes". 
Estas pessoas aceitariam se vender em troca de algum cargo em gabinete de vereador, prefeito e viceprefeito. Além disso, "aqueles que se dizem líderes" disseminam ódio e inveja entre si, espalhando boatos, fofocas, causando discórdia. (Diário de Campo, 4 de abril de 2018)

Nesta linha, a questão da fofoca tem um papel de destaque. Para Elias e Scotson (200o), fofocas são fenômenos cuja dinâmica explicita normas, crenças e relações de uma comunidade, sejam depreciativas ou elogiosas; elas são faces da mesma moeda, servindo para afirmar uma opinião dominante, consolidar ou desfazer relações, afastar ou aproximar pessoas, sendo, portanto, ferramenta poderosa na comunicação e instrumento de controle social. Neste caso, a fofoca tem um papel bastante negativo nos vínculos entre as pessoas da comunidade.

A fofoca é fonte de discórdia e muitas brigas entre os moradores da comunidade. A internet, através das redes sociais, aparece como algo que intensifica a situação. (Diário de Campo, 14 de novembro de 2017)

Um papel citava fofoca e o grupo [de pesquisa] todo confirmou enfaticamente sua existência em todos os lugares e relações na comunidade. (Diário de Campo, 14 de setembro de 2018)

No processo de socialização e organização comunitária, a violência tem contribuído para o esgarçamento do tecido social. Dentre estas, a organização do tráfico de drogas tem interferido na dinâmica cotidiana ditando regras de conduta e convivência (Medeiros; Sapori, 2010). Neste território, as lideranças constatam o poder exercido pelo tráfico na organização da dinâmica comunitária.

Na época das gangues e no período em que o Terceiro Comando estava à frente do tráfico no bairro, aconteciam muitos assaltos e a comunidade era muito mais violenta. Era comum, por exemplo, ver no rio cadáveres e cabeças boiando, corpos de pessoas provavelmente assassinadas pelas gangues. Hoje em dia isso não acontece mais. Os conflitos são resolvidos pelo tráfico [...] embora situações de briga de rua e mortes a esmo não aconteçam mais, reconhece que outros tipos de violência foram trazidos ao bairro. (Diário de Campo, 4 de dezembro de 2017)

A minimização da presença do Estado provocando situações de desamparo social (Dimenstein; Cirilo Neto, 2020) favorece a instalação e o crescimento das organizações do tráfico de drogas e a violência daí decorrente, segundo Zaluar (1997), um problema de difícil resolução nos planos prático e ideológico.

As fragilidades acima se inserem num contexto de extrema pobreza e falta de saneamento básico que colocam cotidianamente em risco a saúde física e mental dos habitantes, condição que gera um sentimento de humilhação e agrava o sofrimento, uma vez que o lugar onde se mora reflete na dignidade, como descrito no livro Quarto de despejo (Jesus, 2007).

\section{Potencialidades expressas nas formas de organização e socialização e nos processos participativos das lideranças da comunidade}

Para Martin-Baró (2017), a percepção das injustiças sociais desencadeia um processo de conscientização, que aliadas aos recursos subjetivos e intersubjetivos podem despertar diferentes formas de enfrentamento. Ainda segundo Martin-Baró (1997), à medida que decodifica gradualmente o mundo que o circunda, o sujeito capta os mecanismos que o oprimem e desumanizam, transformando a consciência que percebe a situação como natural e abrindo os horizontes para novas possibilidades.

[Barreto] contou sobre o seu papel junto com a Martina na luta do ISAC [Instituto Socioambiental e Cultural], pois a cava 4 também traz prejuízos para a classe dos pescadores que tem seu produto de trabalho contaminado e por isso sem possibilidade de ser comercializado ou consumido. Ele destacou

4 Localizada no canal do rio Piaçaguera, a cava armazena 2,6 milhões de metros cúbicos de sedimentos que tem contaminantes banidos pela Convenção de Estocolmo sobre os Poluentes Orgânicos, os níveis de poluição encontrados superam em quatro vezes o maior nível já descrito na literatura do gênero (Mesquita, 2019). 
a importância de conscientizar a população sobre os riscos a que estão expostos devido a presença das cavas para descarte de lixo de metais pesados por empresas que dizem buscar o progresso, porém através de desinformação e desrespeito. (Diário de Campo, $1^{\circ}$ de março de 2018)

A consciência crítica que surge frente a realidade que lhe circunda proporciona uma nova práxis que por sua vez abre para novas formas de consciência. Para Martin-Baró (1997), o processo de conscientização tem como consequência o fortalecimento dos sujeitos e da comunidade, pois as pessoas percebem que as situações de opressão que vivem são compartilhadas pelas outras pessoas da comunidade.

por isso que eu falo pros pescador, não é com discurso que a gente vai [...] a gente só vai conseguir mudar alguma coisa quando a gente tiver informação $e$ depois a gente trabalhar essa informação depois ver qual que émelhor pra todos. Entendeu? $\varepsilon$ isso daínão é uma coisa simples "plim!" da noite pro dia, a gente tem que ver, legislação, lei, regra, o que cabe a nós fazer, pra esse comum. (Barreto)

O ser humano se transforma à medida que modifica a sua realidade, tratando-se de um processo dialético que segundo o autor só pode acontecer através do diálogo entre os sujeitos (MartinBaró, 1997; Montero, 2010).

Oh, ontem eu estava conversando com algumas mulheres daqui da nossa rua, a gente tá formando uma comissão pra gente ir lá na biqueira conversar com eles sobre o baile funk que eles estão fazendo aqui. (Petra)

aí a gente começou a se organizar no Clube de mães pra poder ver como é que a gente podia reivindicar [...] aí o grande empecilho era a rede ferroviária, e o padre Antônio ajudou muito nessa construção [...] chegou a juntar equipe, pessoa [...] dar um ônibus levar até a assembleia legislativa pra pressionar deputado, pra pressionar o Serviço de Patrimônio da União/ SPU, porque não entrava ambulância, não entrava quando morria alguém. (Martina)
A conscientização de uma situação de privação leva um grupo a se organizar para reivindicar seus direitos ou para criar soluções, um grupo que se mobiliza começa a demandar melhores condições de vida. Como apontado por Touraine (2007), por terem vivido a dominação masculina em suas vidas, as mulheres podem vir a ter ações mais gerais pela recomposição da vida.

E eu vi que aqui as crianças tinham uma situação de risco muito grande, além da pobreza, né, era a saúde, era tudo: a situação era precária, muito mais do que nós vemos agora, né? Era criança andando pelada na rua por não ter roupa pra vestir [...] $\varepsilon$ aí como eu já conhecia o Exército da Salvação em Santos, então eu convidei, que quem estava lá era a Margareth Ingrid. Eu convidei ela pra poder vir fazer esse trabalho aqui na comunidade. (Petra)

[Uma assistente social] Ajudou a parte de organização, como de orientação [...] como a gente se orientar se organizar pra gente poder registrar, pra gente poder existir de fato. Porque a sociedade aí já tinha estatuto, mas não era registrado porque não tinha dinheiro, [...] a gente não sabia os caminho como registrar, ia registrar mas não era legalizada então a gente existia meio clandestina, tinha uma organização interna mas não era legalizado. Então a primeira entidade legalizada foi as mulheres que fizeram. Fomos nós. [...] é a Associação Comunitária [...] que existe até hoje. (Marina)

A presença ativa das lideranças femininas desde o princípio, alicerçado em processos de conscientização, tem aberto possibilidades de uma nova práxis, inclusive participando efetivamente na organização e mobilização coletiva no atual contexto da pandemia da COVID-19.

\section{A pandemia da COVID-19 e o acirramento dos efeitos das desigualdades sociais}

Grande parte da população que já vinha sofrendo com a carência dos direitos fundamentais, teve agravada a situação pelos cortes de investimento propostos pela PEC 241, que ao assumir que os problemas econômicos do país são provocados pelos 
gastos públicos, justificou a contenção de programas sociais que vinham combatendo as enormes desigualdades sociais, colocando diretamente em risco os direitos sociais (Fiocruz, 2016).

Neste contexto, chegou ao Brasil em $2020^{5}$ a pandemia da COVID-19, que com o seu avanço explicitou as consequências da desigualdade social, ao afetar mais diretamente as populações com maiores dificuldades de colocar em prática o isolamento e o distanciamento social devido à necessidade de luta pela sobrevivência e a precariedade das moradias (Caponi, 2020; Santos, 2020). Neste caso, como explicitam Nakamura e Silva (2020, p. 156),

os corpos são distintamente vulneráveis à infecção, ao acesso aos serviços de saúde, ao adoecimento e, portanto, à morte decorrente, entre outras coisas, da ausência de políticas públicas que exigem estratégias sanitárias articuladas a outras iniciativas para responder aos diversos aspectos implicados no necessário enfrentamento da pandemia.

Por outro lado, verificamos a "constituição de redes de solidariedade, de iniciativas e respostas comunitárias que, como em outros desafios sanitários já vividos, são elos fundamentais na construção de respostas que têm nos exigido reflexões ininterruptas" (Nakamura; Silva, 2020, p. 157), como aconteceu nesta comunidade que, apesar de todo o estresse, contou com a solidariedade dos moradores, cooperação necessária para enfrentar a minimização da presença das instituições democráticas.

o nível de estresse das pessoas aumentou mais, a gente viu que as pessoas ficaram mais impacientes, eu mesmo presenciei por incrível que pareça umas três agressões contra mulher. (Martina)

o desemprego aumentou também, aumentou a dificuldade, aumentou muito, é porque aqui é uma comunidade muito carente, a fartura aqui é muito grande, farta tudo né, mas ao mesmo tempo sobra solidariedade [...] a solidariedade aumentou muito. (Martina)
As lideranças também conseguiram se organizar para enfrentar a disseminação do vírus ao conscientizar os moradores, utilizar os recursos oferecidos pela tecnologia e fazer parcerias com empresas e organizações para obtenção dos itens necessários para a proteção.

a gente fez um grupo de internet chamado galera do bem, formado por jovens na maioria, porque aqui a gente é muito solidário um com o outro, então dependendo da necessidade, do que tá acontecendo, é como se aciona assim um alarme, sabe, em cada um, então todo mundo se mobiliza. (Martina)

resolvi fazer esse trabalho de conscientização, fizemos parcerias com algumas organizações, recebemos doações de álcool gel, máscara, sabão líquido, enchemos garrafas colocamos em pontos estratégicos, fizemos cartazes, começamos a fazer este trabalho para que as pessoas fossem se conscientizando [...] aí começamos a fazer parcerias com outras organizações, conseguimos cestas básicas, doações para tá colaborando com outras pessoas que não tinham alimento... isso no auge da pandemia. (Martina)

Agregar a participação social e o trabalho coletivo tornou possível às lideranças se colocarem como sujeitos da história e assumirem o papel que o Estado capitalista neoliberal está deixando de cumprir. Sabem que, conforme nos lembra Scaramboni (2020, p. 14), "a importância das vidas está nas ações construídas pelas coletiVIDAdes, que teimam em viver e fomentar projetos de sociedade que impliquem não no extermínio de pessoas, mas sim no fim das desigualdades". Enfrentam as adversidades como podem, apesar do conjunto de afetos que a pandemia está mobilizando e intensificando, principalmente os negativos, geradores de sofrimento psíquico, como o medo, a raiva, a inveja, a saudade. Mas mobilizam também a esperança, "parceira constante (o medo alimenta a esperança e a esperança nos permite viver apesar do medo)" (Sawaia, 2020, p. 4).

5 Em 26 de fevereiro de 2020 foi confirmado no Brasil o primeiro caso na cidade de São Paulo (Croda; Garcia, 2020). 
A respeito disso, Scaramboni (2020, p. 11) enfatiza que:

Nesses caminhos mortíferos, o primeiro desafio é manter-se vivo, é manter a relação com a possibilidade de viver. É tecer uma produção de cuidados e de práticas de enfrentamentos à recusa da morte, com informação, máscaras, água, sabão, estratégias de redução de danos e o que mais seja possível.

A pandemia da COVID-19 tem trazido consequências que extrapolam as médicas e epidemiológicas, por exemplo: os impactos sociais, políticos e econômicos, provocando um acirramento das precariedades já existentes como a miséria, a vulnerabilidade pela ausência dos direitos fundamentais, a insalubridade das habitações, somando-se a tudo isto a carência de intervenções do Estado ou de investimentos privados, trazendo às vésperas do término do auxílio emergencial no país, inúmeros desafios para as lideranças.

\section{Considerações finais}

Verificamos que as lideranças da comunidade têm uma história de conquistas com relação às melhorias das condições de vida a despeito da existência do que consideramos fragilidades como, por exemplo, a atual falta de mobilização existente na comunidade, a percepção desmotivadora da corrupção e a desarticulação entre as lideranças e a violência da organização do tráfico de drogas.

Apesar da existência de potencialidades como os processos de conscientização, organização e diálogo com a comunidade para atingirem alguns objetivos - tais como a criação do Clube das Mães e a organização de um instituto contra a cava (ISAC) -, grande parte das ações ainda não resultou em uma efetivação de direitos e políticas públicas de saúde, educação, assistência ou cultura.

A precarização das condições de vida na comunidade, acentuada pela presença da pandemia, se coloca como um disparador da participação social, pois esta se torna uma necessidade concreta na atualidade. A questão que se apresenta é: como fomentar a participação social para além do voluntarismo?
A presença seletiva do Estado nesta e em outras comunidades fez surgir novos movimentos de participação social, atores e lideranças. Despontaram a igreja e o tráfico, ambas cumprindo funções distintas, mas atuando muitas vezes em um campo comum: o assistencialismo.

Constatamos que um dos grandes desafios é o de fazer com que as pessoas se apropriem do território, impulsionando processos democráticos e participativos voltados ao combate das injustiças e dos sofrimentos das populações postas à margem por uma institucionalização cujas origens remontam ao colonialismo e ao patriarcalismo que marcam as origens de nosso país.

São estes processos que, ao denunciarem as desigualdades sociais, podem fazer progredir as políticas públicas e reconduzir o Estado para um caminho de maior equidade social, sendo, portanto, um importante objeto de pesquisa e reflexão científicas.

Este trabalho sofre da lacuna em relação ao desenvolvimento de outros temas relacionados ao fenômeno da participação social, tais como: a superação do assistencialismo e voluntarismo; a questão do gênero, tendo em vista o protagonismo das mulheres nesta comunidade; os aspectos que levam à liderança nesta comunidade e o papel que o Estado desempenha nas comunidades vulneráveis.

Estas questões permanecem como temas de desejável investigação futura com o propósito de contribuir para o necessário enfrentamento das desigualdades.

\section{Referências}

AGUIAR, N. Patriarcado, sociedade e patrimonialismo. Sociedade e Estado, Brasília, DF, v. 15, n. 2, p. 303-330, 2000. DOI: 10.1590/ So102-69922000000200006

ANHAS, D. M. Construção e fortalecimento de redes de sociabilidade comunitária entre jovens moradores da periferia cubatense. 2019. Tese (Doutorado em Ciências da Saúde) - Universidade Federal de São Paulo, Santos, 2019

ANHAS, D. M.; ROSA, K. R. M.; CASTRO-SILVA, C. R. Afetividade e práxis transformadora na 
pesquisa qualitativa. Psicologia \& Sociedade, Recife, v. 30, e173315, 2018. DOI: 10.1590/18070310/2018v30173315

ANHAS, D. M.; CASTRO-SILVA, C. R. Participação social e subjetividade: vivências juvenis em uma comunidade vulnerável. Psicologia: Teoria e Prática, São Paulo, v. 19, n. 3, p. 139-148, 2017. DOI: 10.5935/1980-69o6/psicologia.v19n3p139-148

BOCK, A. M. B. A psicologia sócio-histórica: uma perspectiva crítica em psicologia. In: BOCK, A. M. B.; GONÇALVES, M. R.; FURTADO, O. (Org.). Psicologia sócio-histórica: uma perspectiva crítica em psicologia. São Paulo: Cortez, 2011. p. 15-35.

BREMAEKER, F. E. J. Os municípios bilionários em 2018. Rio de Janeiro: Observatório de Informações Municipais (OIM), 2019. Disponível em: <https://bit.ly/2OBsDXD>. Acesso em: 12 dez. 2020.

CAPONI, S. Covid-19 no Brasil: entre o negacionismo e a razão neoliberal. Estudos Avançados, São Paulo, v. 34, n. 99, p. 209-224, 2020.

CARRO, R. Uma em cada três cidades com orçamento maior que R\$ 1 bilhão está em São Paulo. O Globo, Rio de Janeiro, 17 set. 2020. Disponível em: <https://glo.bo/2PDzwsd >. Acesso em: 12 dez. 2020.

COSTA, S. L.; CASTRO-SILVA, C. R. Afeto, memória, luta, participação e sentidos de comunidade. Pesquisas e Práticas Psicossociais, São João delRei, v. 10, n. 2, p. 283-291, 2015. Disponível em: <https://bit.ly/3wMzuyX>. Acesso em: 12 dez. 2020.

CRODA, J. H. R.; GARCIA, L. P. Resposta imediata da Vigilância em Saúde à epidemia da covid-19. Epidemiologia e Serviços de Saúde, Brasília, DF, v. 29, n. 1, e2020002, 2020. Disponível em: <https://bit.ly/3cWxMmt>. Acesso em: 4 dez. 2020.

DELENOGARE, L. G. C.; ARAÚJO, M. A. D. Participação social e política no Brasil: revisão sistemática de literatura. In: CIDESP - CONGRESSO INTERNACIONAL DE DESEMPENHO DO SETOR PÚBLICO, 2., 2018, Florianópolis. Anais [...]. Florianópolis, 2018. p. 1427-1447. Disponível em: <https://bit.ly/3fZmujv>. Acesso em: 12 dez. 2020.
DEMO, P. Pesquisa e informação qualitativa: aportes metodológicos. Campinas, SP: Papirus. 2012.

DIMENSTEIN, M.; CIRILO NETO, M. Abordagens conceituais da vulnerabilidade no âmbito da saúde e assistência social. Pesquisas e Práticas Psicossociais, São João del-Rei, v. 15, n. 1, e2935, 2020. Disponível em: <https://bit.ly/2Rlo2H9>. Acesso em: 16 fev. 2021.

ELIAS, N.; SCOTSON, J. L. Os estabelecidos e os outsiders. Rio de Janeiro: Zahar, 2000.

FIOCRUZ - FUNDAÇÃO OSWALDO CRUZ. Fiocruz divulga carta A PEC 241 e os impactos sobre direitos sociais, a saúde e a vida. Portal Fiocruz, Rio de Janeiro, 2016. Disponível em: <https://bit.ly/2Q8adoY>. Acesso em: 15 mar. 2021. FREIRE, P. Conscientização: teoria e prática da libertação: uma introdução ao pensamento de Paulo Freire. São Paulo: Cortez \& Moraes, 1979. GOHN, M. G. Teorias sobre a participação social: desafios para a compreensão das desigualdades sociais. Caderno CRH, Salvador, v. 32, n. 85, p. 63-81, 2019. DOI: 10.9771/ccrh.v32i85.27655 GONZÁLEZ-REY, F. Pesquisa qualitativa em psicologia: caminhos e desafios. São Paulo: Cengage Learning, 2011.

IBGE - INSTITUTO BRASILEIRO DE GEOGRAFIA E ESTATÍSTICA. Setor 351350405000136: síntese dos dados. Censo 2010, Rio de Janeiro, 2010. Disponível em: <https://bit.ly/323K4Db>. Acesso em: 8 abr. 2021.

IPVS. Índice de vulnerabilidade social em Cubatão (2018). Disponível em: https://bit.ly/2Rjozex.

Acesso em: 12 dez. 2020.

JESUS, C. M. Quarto de despejo. São Paulo: Ática, 2007.

LAVALLE, A. G. Participação: valor, utilidade, efeitos e causa. In: PIRES, R. R. (Org.). Efetividade nas instituições participativas no Brasil: estratégias de avaliação. Brasília, DF: Ipea, 2011. p. 33-43.

MARTIN-BARÓ, I. O papel do psicólogo. Estudos de Psicologia, Natal, v. 2, n. 1, p. 7-27, 1997. DOI: 10.1590/S1413-294X1997000100002 
MARTIN-BARÓ, I. Crítica e libertação na

psicologia: estudos psicossociais. Petrópolis, RJ:

Vozes, 2017.

MEDEIROS, R.; SAPORI, L. F. (Org.). Crack: um desafio social. Belo Horizonte: Editora PUC-MG, 2010.

MERGEN, J.; ZANETTI, V.; RESCHILIAN, P. R. Estatuto da cidade e cidadania: reflexões sobre a participação popular e gestão democrática na revisão do plano diretor de desenvolvimento integrado de São José dos Campos/SP (2016). Revista Univap, São Paulo, v. 24, n. 46, p. 129-143, 2018.

MESQUITA, J. L. Cavas subaquáticas: projeto que proíbe construção avança. Estadão, São Paulo, 2019. Disponível em: <https://bit.ly/3doogmP>. Acesso em: 12 dez. 2020.

MONTERO, M. Crítica, autocrítica y construcción de teoría en la psicología social latinoamericana. Revista Colombiana de Psicología, Bogotá, DC, v. 19, n. 2, p. 177-191, 2010. Disponível em: <https://bit.ly/3mwUV1T>. Acesso em: 6 dez. 2020.

MOURA, C. Sociologia do negro brasileiro. São Paulo: Perspectiva, 2019.

NAKAMURA, E.; SILVA, C. G. O contexto da pandemia do covid-19: desigualdades sociais, vulnerabilidade e caminhos possíveis. In: GROSSI, M. P.; TONIOL, R. (Org.). Cientistas sociais e o coronavírus. São Paulo: Anpocs, 2020. p. 154-158.

RODRIGUES, V. P. et al. Respostas à pandemia em comunidades vulneráveis: uma abordagem de simulação. Revista de Administração Pública, Rio de Janeiro, v. 54, n. 4, p. 1111-1122, 2020. Disponível em: $<$ https://bit.ly/3cYmLB1>. Acesso em: 18 mar. 2021.

SANTOS, B. S. A cruel pedagogia do vírus.

São Paulo: Boitempo, 2020.

SAWAIA, B. B. Família e afetividade: a

configuração de uma práxis ético-política, perigos e oportunidades. In: ACOSTA, A. R.; VITALE, M. A. F. (Org.). Família: redes, laços e políticas públicas. São Paulo: IEE/Pusp, 2003. p. 39-50.

SAWAIA, B. B. Transformação social: um objeto pertinente à psicologia social?. Psicologia \& Sociedade, Belo Horizonte, v. 26, p. 4-17,
2014. Número especial 2. DOI: 10.1590/So10271822014000600002

SAWAIA, B. B. Apresentação. In: SAWAIA, B. B. et al. (Org.). Expressões da pandemia. São Paulo: Nexin/Nepam, 2020. v. 5, p. 4-8.

SCARAMBONI, K. ColetiVIDAdes em tempos de pandemia. In: SAWAIA, B.B. et al. (Org.). Expressões da pandemia. São Paulo: Nexin/ Nepam, 2020. v. 5, p. 10-14.

THOMPSON, J. B. Ideologia e cultura moderna: teoria social crítica na era dos meios de comunicação de massa. Petrópolis, RJ: Vozes., 2000.

TOURAINE, A. O mundo das mulheres. Petrópolis, RJ: Vozes., 2007.

VIEIRA, E. M.; XIMENES, V. M. Conscientização: em que interessa este conceito à psicologia. Psicologia Argumento, Curitiba, v. 26, n. 52, p. 23-33, 2008.

WSR - WORLD SOCIAL REPORT. Inequality in a rapidly changing world. New York: United Nations, 2020.

ZALUAR, A. Exclusão e políticas públicas: dilemas teóricos e alternativas políticas. Revista Brasileira de Ciências Sociais, São Paulo, v. 12, n. 35, p. 21-32, 1997.

\section{Agradecimentos}

Agradecemos aos/às pareceristas anônimos/as e aos/às revisores/ as do periódico pela leitura cuidadosa e pelas contribuições que conferiram melhorias ao texto.

\section{Contribuição dos autores}

Yagiu participou do gerenciamento e da análise das informações, redação, revisão crítica e aprovação da versão final. Castro-Silva, Euzebios Filho e Martin participaram da redação, revisão crítica e aprovação da versão final.

Recebido: 26/03/2021

Aprovado: 29/03/2021 